\title{
How Academic Dentistry will Emerge from this Economic Crisis?
}

\section{Sompop Bencharit*}

Assistant Professor, Department of Prosthodontics, School of Dentistry, Department of Pharmacology, School of Medicine, University of North Carolina at Chapel Hill

Recent economic crisis leading to severe budget cuts in both governmental and private sectors has a significant impact in current dental research and academic dentistry. In the dental schools, its shortterm implications include raising tuition and fees, eliminating staff and faculty appointments or positions, and restricting funding to teaching and research activities. The long-term implications to this world-wide budget cut are not clear. While we can look at this crisis as an end to our free spending in research and other academic activities, we can respond to this crisis logically and effectively.

In general, dental schools have three common missions including teaching, research, and clinical services. Obviously the teaching and research missions will be the most harshly affected by the crisis. Part-time and non-tenured faculty and supporting staff members are perhaps some of the first to be let go [1]. The school will have to raise tuition while maintaining or increasing the dental student class size. Combining this with the reduction of faculty, the student-faculty ratio will be significantly increased. The faculty will be asked to do more with no pay-raise or even with salary reduction. In regards to the research mission, it will be difficult for schools to recruit and retain good researchers. Limited budgets allocated to faculty recruitment and faculty development may result in more to-be-academic dentists going into private practice rather than academia. Not only will this crisis cause personnel problems, it will also reduce funding opportunities for dental research. For example, the budgets for the National Institute of Dental and Craniofacial Research (NIDCR) from 2000 to 2003 increase yearly about 8 to $15 \%$; however from 2004 to 2010 the yearly increase of the budget range from $-1 \%$ ( $1 \%$ decrease) to $3.32 \%$ [2]. This yearly increase in budgets is hardly keeping up with the yearly inflation rate and increased number of grant applications.

While almost all dental schools use similar short-term strategies to deal with the crisis, there is no clear concession of the long-term solution. Since most schools can no longer rely on state appropriation, tuition and clinical income increasingly become a major reliable source for the school budget. Therefore, it is logical for most schools to expand the clinical programs and student/faculty practices. This in short-term may be a good solution and improve the mission of clinical patientcare/community services. If overemphasis is made on the clinical practices alone, it can have terrible immediate and long-term impacts in the teaching and research missions. Clinical faculty members will be distracted from teaching and will have even less time to do research.

In order to respond to this crisis effectively, restructuring of the preclinical and clinical teaching curricula will be required [3]. Revising and restructuring preclinical courses can help to remove redundancy in teaching [4]. Using multichannel approaches and embracing modern teaching technologies such as podcast, web-based learning, etc, will enhance teaching and limit lecture hours so faculty can save their time for other activities such as research $[5,6]$. While it is easy to add more students in the lecture hall with one professor, it is a lot more difficult to teach preclinical laboratories and clinics with a high student-faculty ratio. We have to be more creative in our integration of pre-clinical and clinical courses. For instance, we can reduce student-faculy ratio in most clinics by reducing general laboratory and clinical requirements. At the same time we can increase specialty-based elective courses and clinics for only students who are interested in certain fields.

The most important key to prevent long-term consequence in the research mission is perhaps to revising and restructuring the dental school's research programs and entities. Traditionally, one principle investigator-one laboratory approach worked well in the past when there were more funding opportunities. In this crisis, we will have to reassess our past approaches. The dental school should select its main research goals and missions and then put their budgets and faculty development programs toward these goals/missions. Recruiting and retaining diverse faculty expertise by building a common research space for common research goals may help improve success in obtaining extramural grants. In addition to combining this effort, it will be crucial to reach out to other institutions to seek and share expertise. Integration of the research mission into the teaching and clinical missions will also help reduce redundancy and improve all missions at the same time $[7,8]$.

This economic crisis clearly affects all aspects of academic dentistry. However, we can turn this crisis into opportunity. Now is the time to not only think of short-term solutions, but also to think of how we would embrace this crisis and deal with it longitudinally. Reorganization and integration within each dental school is now needed. Integration of clinical teaching and clinical/translational research components to clinical service expansion will be needed. Improvement in faculty development programs and recruitment based on a balanced program in teaching, research and services with a common research goal will be key in preventing long term consequences. I hope that we will learn from this crisis and take this opportunity to improve the academic core missions of our dental school system.

\section{References}

1. Chmar JE, Weaver RG, Valachovic RW (2008) Dental school vacant budgeted faculty positions, academic years 2005-06 and 2006-07. J Dent Educ 72: 370 385 .

2. http://www.fnidcr.org/patient/nihNidcrFunding.html

3. Valachovic RW (2008) The case for change in dental education. N Y State Dent J 74: 20-22.

*Corresponding author: Sompop Bencharit, DDS, MS, PhD, FACP, Assistant Professor, Department of Prosthodontics, School of Dentistry, Department of Pharmacology, School of Medicine, University of North Carolina at Chapel Hill, CB\#7450, Chapel Hill, NC 27599-7450, USA, E-mail: Sompop_Bencharit@ dentistry.unc.edu

Received August 03, 2011; Accepted August 05, 2011; Published August 09 2011

Citation: Bencharit S (2011) How Academic Dentistry will Emerge from this Economic Crisis? Dentistry 1:e101. doi:10.4172/2161-1122.1000e101

Copyright: (c) Bencharit S. This is an open-access article distributed under the terms of the Creative Commons Attribution License, which permits unrestricted use, distribution, and reproduction in any medium, provided the original author and source are credited. 
4. Haden NK, Hendricson WD, Kassebaum DK, Ranney RR, Weinstein G, et al. (2010) Curriculum change in dental education, 2003-09. J Dent Educ 74: 539557

5. Kerfoot BP, DeWolf WC, Masser BA, Church PA, Federman DD (2007) Spaced education improves the retention of clinical knowledge by medical students: a randomised controlled trial. Med Educ 41: 23-31.

6. Kerfoot BP, Baker H, Jackson TL, Hulbert WC, Federman DD, et al. (2006)
Multi-institutional randomized controlled trial of adjuvant Web-based teaching to medical students. Acad Med 81: 224-230.

7. De Paoli P (2009) Institutional shared resources and translational cancer research. J Transl Med 7: 54

8. Kulage KM, Larson EL, Begg MD (2011) Sharing facilities and administrative cost recovery to facilitate interdisciplinary research. Acad Med 86: 394-401. 